\title{
Feedforward Inhibition Contributes to the Control of Epileptiform Propagation Speed
}

\author{
Andrew J. Trevelyan, ${ }^{1,2}$ David Sussillo, ${ }^{1}$ and Rafael Yuste ${ }^{1}$ \\ ${ }^{1}$ Department of Biological Sciences, Howard Hughes Medical Institute, Columbia University, New York, New York 10027, and ${ }^{2}$ School of Neurology, \\ Neurobiology, and Psychiatry, The Medical School, University of Newcastle, Newcastle NE2 4HH, United Kingdom
}

It is still poorly understood how epileptiform events can recruit cortical circuits. Moreover, the speed of propagation of epileptiform discharges in vivo and in vitro can vary over several orders of magnitude $(0.1-100 \mathrm{~mm} / \mathrm{s})$, a range difficult to explain by a single mechanism. We previously showed how epileptiform spread in neocortical slices is opposed by a powerful feedforward inhibition ahead of the ictal wave. When this feedforward inhibition is intact, epileptiform spreads very slowly ( $\sim 100 \mu \mathrm{m} / \mathrm{s})$. We now investigate whether changes in this inhibitory restraint can also explain much faster propagation velocities. We made use of a very characteristic pattern of evolution of ictal activity in the zero magnesium $\left(0 \mathrm{Mg}^{2+}\right)$ model of epilepsy. With each successive ictal event, the number of preictal inhibitory barrages dropped, and in parallel with this change, the propagation velocity increased. There was a highly significant correlation $(p<0.001)$ between the two measures over a 1000-fold range of velocities, indicating that feedforward inhibition was the prime determinant of the speed of epileptiform propagation. We propose that the speed of propagation is set by the extent of the recruitment steps, which in turn is set by how successfully the feedforward inhibitory restraint contains the excitatory drive. Thus, a single mechanism could account for the wide range of propagation velocities of epileptiform events observed in vitro and in vivo.

Key words: epilepsy; seizure; calcium imaging; inhibition; pyramidal cell; neocortex

\section{Introduction}

We lack a coherent view of epileptiform propagation. The various in vitro models of epilepsy display a large range of propagation speeds, extending over almost three orders of magnitude. Specifically, disinhibition of neocortical slices provokes ictal events, which propagate with great speed $(20-100 \mathrm{~mm} / \mathrm{s})$ (Chervin et al., 1988; Wadman and Gutnick, 1993; Albowitz and Kuhnt, 1995; Pinto et al., 2005; Trevelyan et al., 2006). In contrast, in the zero magnesium $\left(0 \mathrm{Mg}^{2+}\right)$ model, in which ictogenesis is presumed to arise primarily from enhanced excitation (Anderson et al., 1986; Walther et al., 1986), ictal propagation can be extremely slow $(\sim 100-250 \mu \mathrm{m} / \mathrm{s})$ (Wong and Prince, 1990; Trevelyan et al., 2006).

Different speeds of epileptiform spread are also seen in vivo. Propagation can be very slow (Blume et al., 2001), as evident during a Jacksonian march (Jasper, 1969), but in other cases, focal events generalize extremely rapidly (Lemieux and Blume, 1986; Kobayashi et al., 1994). The range of latencies for activation of adjacent subdural electrodes (10 mm separation) is reported to vary from 1 to 45 s (Blume et al., 2001), suggesting a range of

Received Nov. 3, 2006; revised Feb. 12, 2007; accepted Feb. 13, 2007.

This work was supported by the Epilepsy Foundation of America, the National Institute of Neurological Disorders and Stroke, and a Training Program in Molecular Biophysics (GM008281). We declare that we have no competing financial interests. We thank Miles Whittington and Fiona Le Beau for their helpful and supportive comments on previous drafts of this manuscript.

Correspondence should be addressed to Andrew J. Trevelyan at his present address: School of Neurology, Neurobiology, and Psychiatry, The Medical School, University of Newcastle, Newcastle NE2 4HH, UK. E-mail: andytrev@gmail.com.

DOI:10.1523/JNEUROSCI.0145-07.2007

Copyright $\odot 2007$ Society for Neuroscience $\quad 0270-6474 / 07 / 273383-05 \$ 15.00 / 0$ propagation speeds of $<200 \mu \mathrm{m} / \mathrm{s}$ to $>10 \mathrm{~mm} / \mathrm{s}$, taking cortical foldings into account. Rapid generalization has been proposed to occur through thalamic activation, although paired in vivo recordings from cortex and thalamus are not consistent with this view (Steriade and Contreras, 1995; Pinault et al., 1998), suggesting a cortical explanation for both slow and fast propagation (Timofeev and Steriade, 2004).

We have shown previously that powerful feedforward inhibition, manifest ahead of an ictal wavefront, opposes epileptiform propagation (Trevelyan et al., 2006). We now show that feedforward inhibition becomes less effective after repeated ictal events. Consequently, although early events propagate slowly in a stepwise manner, late ictal events generalized rapidly, similar to the rapid generalization seen with disinhibition models of epilepsy. Thus, individual brain slices can display the complete range of propagation velocities, from very slow to very rapid generalization. We find that the speed of ictal propagation correlates highly with the number of preictal barrages that pyramidal cells receive before being recruited to the event. We conclude from this that the feedforward inhibition is the prime determinant controlling how rapidly epileptiform activity spreads.

\section{Materials and Methods}

Slice preparation. All animal handling and experimentation were done according to National Institutes of Health guidelines. Recordings were made from slices of occipital cortex prepared acutely from postnatal day 13-18 C57BL/6 mice. Animals were anesthetized with ketamine-xylazine $(10 \mathrm{mg} / \mathrm{kg})$, and the brain was removed and submerged in ice-cold isotonic sucrose solution (in mM: 222 sucrose, $26 \mathrm{NaHCO}_{3}, 2 \mathrm{MgCl}_{2}, 2.6$ $\mathrm{KCl}, 1.5 \mathrm{NaH}_{2} \mathrm{PO}_{4}{ }^{-}, 0.05$ ascorbic acid). Coronal slices, $350 \mu \mathrm{m}$ thick, 
were cut using a Leica (Nussloch, Germany) vibratome, and the slices were incubated in artificial CSF (ACSF) containing $1 \mathrm{mM} \mathrm{Mg}^{2+}$ ions (in mм: $125 \mathrm{NaCl}, 26 \mathrm{NaHCO}_{3}, 10$ dextrose, $3.5 \mathrm{KCl}, 2 \mathrm{CaCl}_{2}, 1.26$ $\left.\mathrm{NaH}_{2} \mathrm{PO}_{4}{ }^{-}, 1 \mathrm{MgSO}_{4}\right)$.

Dye loading and imaging. Slices were bulk loaded with Oregon Green 488 Bapta 1 (OGB1)-AM ester as described previously (Trevelyan et al., 2006). Astrocytes were identified using the astrocyte-specific marker sulforhodamine (SR101; Invitrogen, Carlsbad, CA) and excluded from the analysis.

OGB1 imaging was performed using a spinning disk confocal (Solamere Technology Group, Salt Lake City, UT) mounted on an upright microscope (BX/50WI; Olympus, Tokyo, Japan). The tissue was illuminated with a $488 \mathrm{~nm}$ laser (Coherent, Santa Clara, CA), controlled through an acoustic-optical tunable filter. Images were collected at 7.5-60 Hz [Stanford Photonics (Palo Alto, CA) Mega camera; QED software (Delta, British Columbia, Canada)]. Off-line analysis was performed using Image $(\mathrm{NIH})$ and in-house software. Line scan analyses were done on movies collected using $4 \times$ or $10 \times$ objectives. A box (up to $1 \mathrm{~mm}$ long and $\sim 40-50 \mu \mathrm{m}$ width) was laid approximately over layer 5 and divided up into $4 \mu \mathrm{m}$ bins aligned to the cortical columns. The average $\mathrm{Ca}^{+}$fluorescence signal for each bin was derived and plotted against time, to give a line scan plot with time as the abscissa and cortical horizontal distance as the ordinate. Cellular $\mathrm{Ca}^{2+}$ signals were derived from movies taken using $20 \times$ and $40 \times$ objectives. Somata were identified as described previously (Cossart et al., 2003; Ikegaya et al., 2004; MacLean et al., 2005). The neuropil signal was subtracted from the somatic signal to derive the "center-surround" (CS) signal, which we found to be a better indicator of the activity pattern of individual cells during intense network activity (Trevelyan et al., 2006).

Electrophysiology. The chamber was mounted on a Scientifica movable top plate fitted with a heater plate (Warner Instruments, Hampden, CT), and the incoming solution (perfusion at $1-3 \mathrm{ml} / \mathrm{min}$ ) was heated by a sleeve heater element (Warner Instruments). All imaging and electrophysiological recordings were done at $33-37^{\circ} \mathrm{C}$. Whole-cell recordings were made using 3-7 $\mathrm{M} \Omega$ pipettes (borosilicate glass; Harvard Apparatus, Holliston, MA; MX130 hydraulic micromanipulators; San Diego Instruments, San Diego, CA) containing the following (in mM): $125 \mathrm{~K}$ methyl-SO,$\quad 10$ K-HEPES, 2.5 Mg-ATP, $6 \mathrm{NaCl}, 5 \mathrm{~N}$-(2,6dimethylphenylcarbomoylmethyl) triethylammonium bromide (QX314; Tocris Bioscience, Ellisville, MO), $0.3 \mathrm{Na}-\mathrm{GTP}, 0.5 \%$ biocytin (w/v). Slices were fixed and stained for biocytin; the location of the stained cells allowed us to ascribe cortical laminar identities to the imaged areas. For current clamp $\left(I_{\text {clamp }}\right)$ recordings of action potential trains, the QX-314 was omitted. For cell-attached recordings, the patch electrode was filled with ACSF. Electrophysiological data were collected using a Heka Elektronik (Lambrecht/Pfalz, Germany) EPC10 amplifier with Patchmaster software and analyzed off-line using Igor (WaveMetrics, Lake Oswego, OR). There were no qualitative differences between the recordings from OGB1-loaded versus unloaded slices.

Analysis of delays. Delays were measured from paired $V_{\text {clamp }}$ recordings (at $-30 \mathrm{mV}$ ) of cells separated by $>300 \mu \mathrm{m}$. Most ictal events were preceded by inhibitory barrages recorded in both cells, and the relative timing of onset of these inhibitory barrages consistently indicated that the event started to one or other side of the pair of cells, and not between the cells, thus allowing for an appropriate measure of the propagation velocity. This view was supported by our line-scan experiments. Time delays were measured between the minima (peak inward current) for the two $V_{\text {clamp }}$ recordings for two reasons: (1) the timing of the peak inward current was consistent for a wide range of holding potentials and thus is not affected by changes (or differences between the cells) in the series resistance (and thus the effective somatic holding potential); (2) the peak inward current consistently corresponded with the peak neuropil $\mathrm{Ca}^{2+}$ signal, local to the electrode, in the line scans (see Fig. $3 A, B$ ). From these line scans, the peak inward current generally occurs simultaneous with, or on the synaptic barrage subsequent to, the seizure invading the cortical column of the recorded cell. Furthermore, estimates of the propagation velocity derived from this analysis were consistent with estimates from line scans for the slowest events (faster events usually traversed the field of view in a single time frame and thus could not be used to determine propagation velocity). The time delays were then normalized to a cell separation of $1 \mathrm{~mm}$; thus, the delays represent the reciprocal of the velocity.

\section{Results}

\section{Progressive loss of preictal barrages}

We combined whole-cell recordings from layer 5 pyramidal cells with $\mathrm{Ca}^{2+}$ imaging of network activity (Badea et al., 2001) to study the evolution of epileptiform activity in slices bathed in 0 $\mathrm{Mg}^{2+}$ ACSF. We were particularly interested in changes in the spread of activity, and this commonly used model of epilepsy seemed well suited to this end: in $0 \mathrm{Mg}^{2+}$, cortical slices show a consistent and characteristic evolution of activity patterns (Dreier and Heinemann, 1990; Pfeiffer et al., 1996) and, crucially, display a range of propagation speeds (Wong and Prince, 1990). Slices were incubated in a conventional, nonepileptogenic ACSF until after the cells were patched and electrophysiology recordings had started. Only then was the $\mathrm{Mg}^{2+}$ washed out, thus enabling an accurate assessment of the time course of the evolution of epileptiform activity. $V_{\text {clamp }}$ recordings from pyramidal cells showed two types of activity induced by the switch to $0 \mathrm{Mg}^{2+}$ ACSF: predominantly inhibitory barrages and rhythmic excitatory full ictal events.

The inhibitory barrages were a transient pattern of activity (Fig. $1 A$ ). In the earliest full ictal events, long runs of these inhibitory barrages preceded the first large excitatory volleys (Fig. $1 B$ ). In contrast, in slices having experienced many ictal events, the late events show an almost immediate switch to excitation (Fig. $1 C)$. In these late events, this first volley was overwhelmingly excitatory, although it was often led by a short (10-100 ms long) flurry of IPSCs (Fig. 1C, open arrowhead). The late events lack any preceding, predominantly inhibitory events.

To quantify this change, we counted the number of predominantly inhibitory barrages after the switch to the regular $\delta$-rhythm of barrages $(0.5-2 \mathrm{~Hz})$ that lead each successive ictal events (Fig. $1 B$, arrows). There was a progressive drop in the number of preceding inhibitory barrages with each successive ictal event (Fig. 2A) (102 ictal events from 20 brain slices). These changes were apparent in recordings in which the series resistance was stable.

We previously showed that the inhibitory barrages immediately preceding an ictal event constitute a powerful feedforward inhibition from already activated regions of cortex and that these barrages serve to delay recruitment of pyramidal cells to the event (Trevelyan et al., 2006). A loss of these inhibitory barrages then should lead to faster neuronal recruitment and thus faster ictal propagation. To test this hypothesis, we examined recordings from pairs of pyramidal cells separated by $>300 \mu \mathrm{m}$. These paired recordings showed a progressive increase in propagation velocity with each successive ictal event (Fig. $2 B)(p<0.05$, multigroup ANOVA). The mean propagation of the first two events (pooled because they did not differ significantly) was $0.105 \pm 0.015 \mathrm{~mm} / \mathrm{s}$ (mean $\pm \mathrm{SEM} ; n=17$; range, $0.019-0.219$ $\mathrm{mm} / \mathrm{s}$ ). The mean speed of late ictal events (after more than six events) was $9.52 \pm 3.80 \mathrm{~mm} / \mathrm{s}$ (mean \pm SEM; $n=13$; range $0.157-47 \mathrm{~mm} / \mathrm{s}$ ). Furthermore, the delay in activation of the later recruited cell was highly correlated with the number of preictal inhibitory events in that cell (Fig. $2 C$ ) $[p<0.001 ; 47$ ictal events from 11 brain slices; range of delays (normalized to $1 \mathrm{~mm}$ separation of cells) was $36 \mathrm{~ms}$ to $53 \mathrm{~s}$, a 1500-fold range].

\section{Visualization of rapid propagation using calcium imaging}

We confirmed this change in propagation velocity using lowmagnification imaging of slices bulk labeled with the $\mathrm{Ca}^{2+}$ dye 


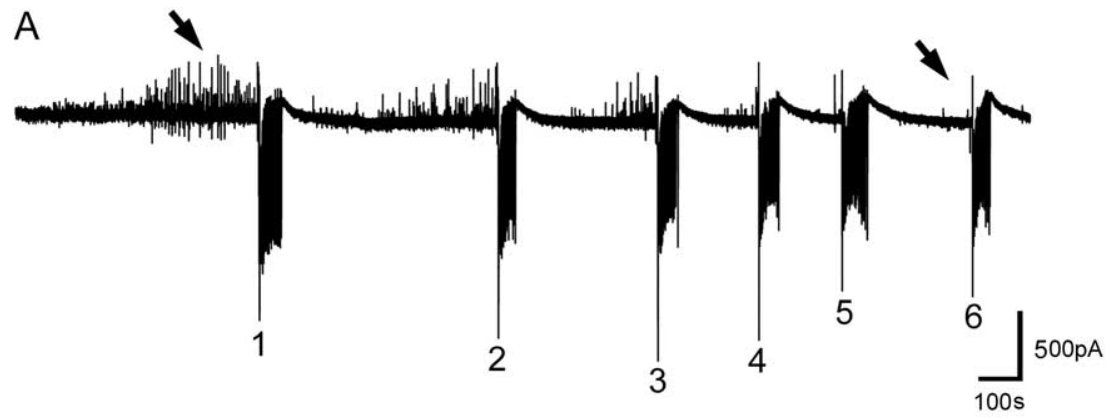

B. Early event
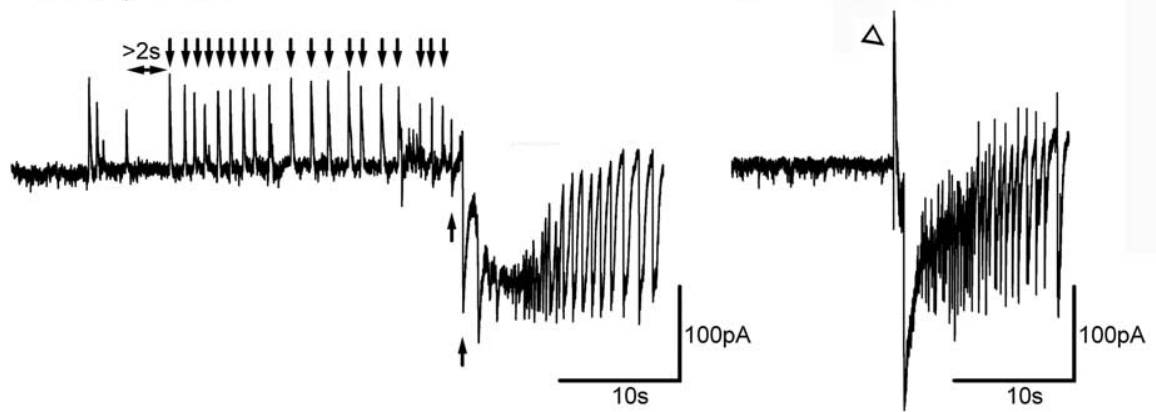

C. Late event

Figure 1. Progressive loss of preictal inhibitory barrages on to pyramidal cells coincides with progressive increase in epileptiform propagation velocity. $A, V_{\text {clamp }}$ recording from a layer 5 pyramidal cell held at $-30 \mathrm{mV}$, approximately half-way between the $\mathrm{GABA}_{A}$ and glutamate reversal potentials. Note the progressive disappearance of inhibitory synaptic volleys (upward deflections; arrows) with successive ictal events (numbered 1-6). $\boldsymbol{B}$, Expanded view of an early ictal event from another layer 5 pyramid, to show how preictal inhibitory barrages were counted for the analysis shown in Figure 2, $A$ and $C$. Counts were made between the time of the switch to the regular $0.5-2 \mathrm{~Hz}$ frequency (i.e., delay of $>2$ s before the first arrow) and the time of the first predominantly excitatory barrage (arrows underneath trace). $\boldsymbol{C}$, Expanded view of a late seizure (the same cell as in $\boldsymbol{B}$ ) showing the absence of rhythmic preictal inhibitory barrages, although the event is preceded by a brief burst of IPSCs (arrowhead).

\section{A. Preictal bursts}

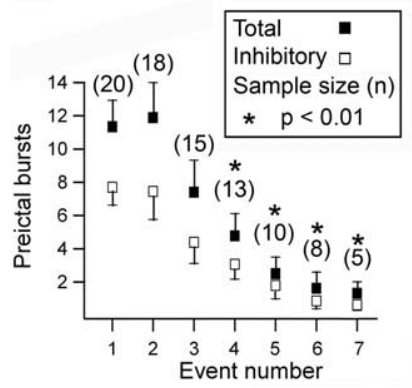

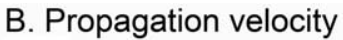

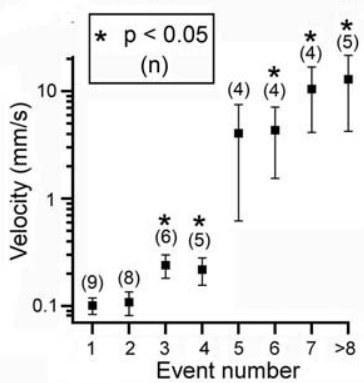

\section{Correlation}

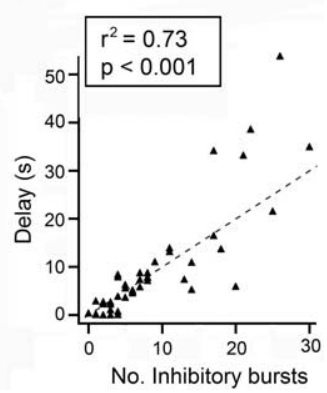

Figure 2. Correlation between loss of preictal barrages and propagation velocity. $A$, Plot showing the reduction in the number of preictal inhibitory barrages with successive ictal events. $\boldsymbol{B}$, The increase in propagation velocity with successive ictal events. In both $\boldsymbol{A}$ and $\boldsymbol{B}$, asterisked data points indicate significant difference from event number $1(p<0.05)$. Error bars show the SEM. $n$ is number of slices. C, Delay between recruitment of pairs of layer 5 pyramidal cells separated by $>300 \mu \mathrm{m}$ plotted against the number of preictal barrages. The delay is normalized to a separation of $1 \mathrm{~mm}$. Thus, the velocity of the event is the reciprocal of this "normalized" delay. There is a highly significant correlation between the delay and the number of inhibitory barrages ( 8 slices; 37 ictal events).

OGB1. Rather than attempt to derive signals from individual cells, we instead took "line scans" through the neuropil of infragranular layers to chart the progression of ictal events, while simultaneously recording layer 5 pyramidal cells (eight slices). Early events progress in a slow, stepwise manner (Fig. $3 A$ ). In contrast, late events engulf the entire field of view within a single time frame, when imaged at $60 \mathrm{~Hz}$ (i.e., in $<17 \mathrm{~ms}$ ) (Fig. 3B). In this way, they strongly resemble ictal events induced by blockade of $\mathrm{GABA}_{\mathrm{A}}$ receptors, which likewise progress across the entire field of view almost instantaneously (Fig. 3C).
We next imaged at a higher magnification to examine the change in the pattern of recruitment of individual neurons. These experiments showed two key differences between the early and late events: first, in the number of steps it took an individual neuron to reach the maximal $\mathrm{Ca}^{2+}$ fluorescence, and second, in the synchronization of recruitment of neurons in the field of view. The typical pattern of neuronal activation in early events was for the firing rate of the cell to ratchet up over several successive synaptic barrages (Fig. $4 A i, B i)$. This pattern was apparent in both electrophysiological recordings and from $\mathrm{Ca}^{2+}$ imaging data. It contrasted sharply with late events, when cells tended to show a single sudden step in the $\mathrm{Ca}^{2+}$ fluorescence change (seen as a single peak in the derivative, or a single white band in the derivative grayscale "raster" plots) corresponding to a step change in firing rate (Fig. 4Aii). Furthermore, this single recruitment event was synchronized in all cells within the field of view, contrasting with the staggered recruitment during early events (Trevelyan et al., 2006). Thus, late ictal events generalized extremely rapidly (Fig. 4C).

\section{Discussion}

Previous studies of epileptiform spread have consistently reported extremely rapid ictal propagation across cortical slice preparations $(20-100 \mathrm{~mm} / \mathrm{s})$ (Chervin et al., 1988; Wadman and Gutnick, 1993; Albowitz and Kuhnt, 1995; Pinto et al., 2005; Trevelyan et al., 2006). The exception is the $0 \mathrm{Mg}^{2+}$ model in which epileptiform activity can propagate up to three orders of magnitude more slowly $(\sim 100$ $250 \mu \mathrm{m} / \mathrm{s}$ ) (Wong and Prince, 1990; Trevelyan et al., 2006). Our recent work showed that the slow propagation in this model was caused by a powerful feedforward inhibition, ahead of the ictal front (Trevelyan et al., 2006). This feedforward inhibition coincides with the phasic excitatory volleys from neurons already recruited to the event and can veto this excitatory drive, thereby causing the wavefront to stall. Because the ictal event does not progress between crisis times, each crisis resisted constitutes a significant delay. In essence, the number of preictal barrages is a tally of the crises that neuron resisted. We now show that there is a very high correlation between the number of preictal barrages and the latency of activation of downstream neurons, over a 1000-fold range of propagation velocities. Thus, the entire range of propagation speeds, from the very fast to the very slow, can be understood in terms of how many network crises are resisted.

A previous study of epileptiform propagation using the 0 $\mathrm{Mg}^{2+}$ model (Wong and Prince, 1990) reported that some slices 

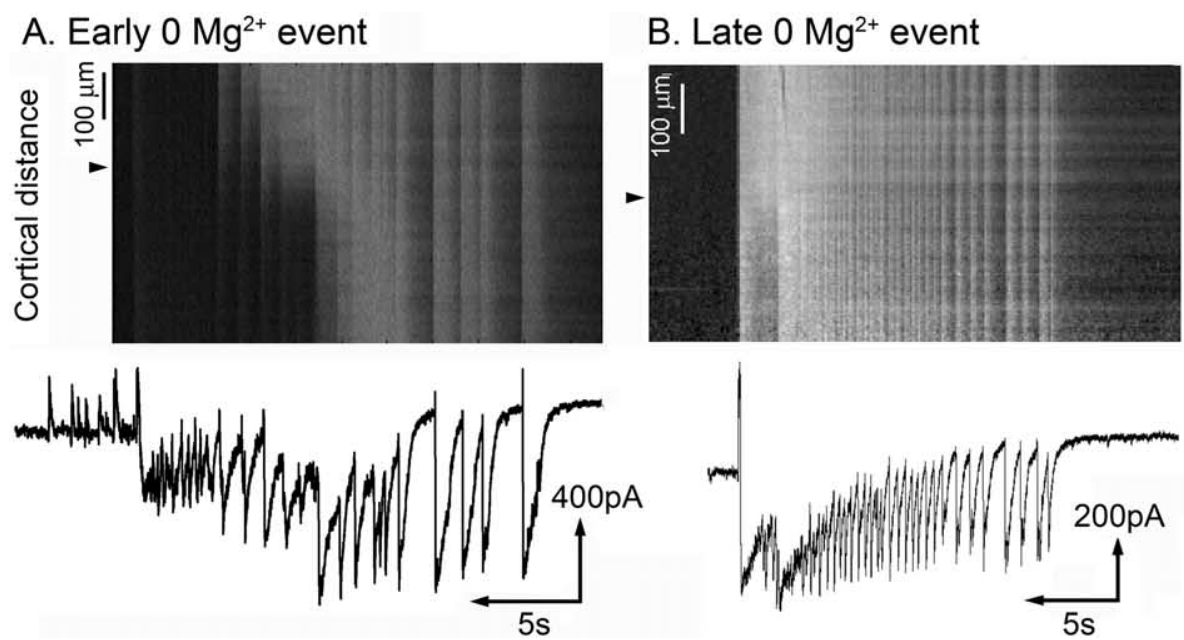

\section{Early gabazine event}
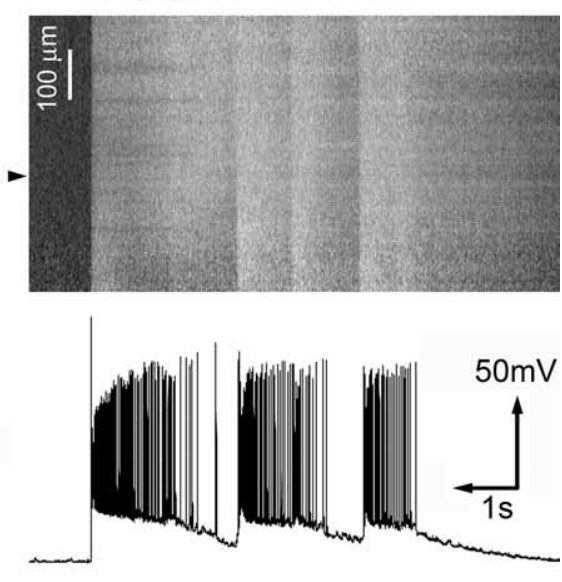

Figure 3. Neuropil calcium imaging demonstrates the transition from slow to rapid propagation. $\boldsymbol{A}$, Line scan through layer 5 during an early $0 \mathrm{Mg}{ }^{2+}$ event, plotted with a $V_{\text {clamp }}$ recording of a layer 5 pyramid held at $-30 \mathrm{mV}$. The locations of the recorded cells within each line scan are indicated by the arrowheads. The line scan clearly shows the discontinuous progress, with a prominent step just beyond the recorded cell. $\boldsymbol{B}$, Linescan of a late $0 \mathrm{Mg}^{2+}$ event together with $V_{\text {clamp }}$ trace from a layer 5 pyramidal cell ( $-30 \mathrm{mV}$; cell location indicated by the dotted line). The entire field of view is incorporated into the ictal event simultaneously. The corresponding $V_{\text {clamp }}$ recording shows the loss of the preceding inhibitory barrages and the first excitatory barrage temporally aligned with the $\mathrm{Ca}^{2+}$ signal. $C$, Linescan view of an ictal event induced by disinhibition, together with a current-clamp recording of a layer 5 pyramidal. These recordings show the extreme rapidity with which individual neurons, and indeed whole tracts of cortex, are recruited to an event when inhibition is compromised.

\section{A. Electrophysiology}

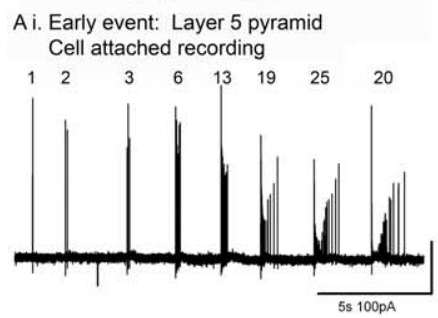

A ii. Late event: Layer 5 pyramid - Iclamp

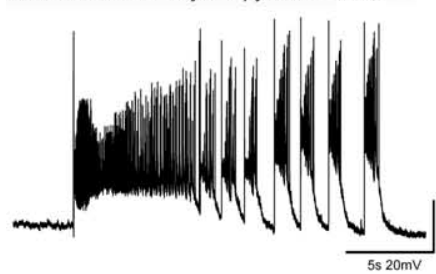

\section{B. Somatic $\mathrm{Ca}^{2+}$ fluorescence}

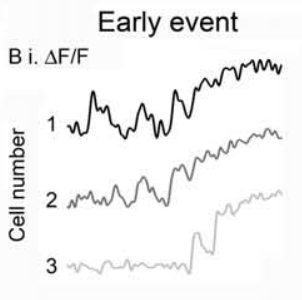

B ii. $d(\Delta F) / d t$

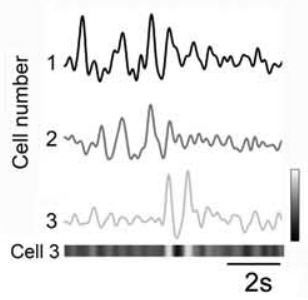

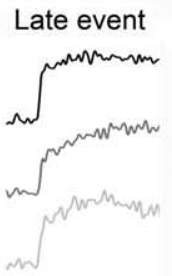

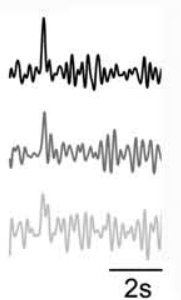

\section{Grayscale plots}

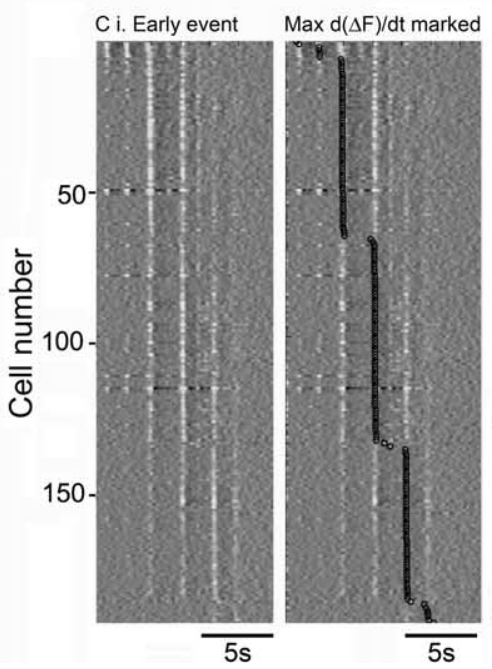

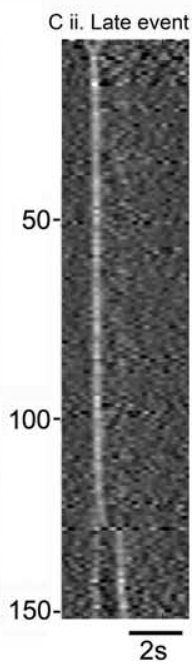

Figure 4. Somatic calcium imaging demonstrates a change in the recruitment pattern of neurons from early to late $0 \mathrm{Mg}^{2+}$ events. $A$, Electrophysiological recordings showing the typical patterns of recruitment of layer 5 pyramidal cells to early (Ai) and late (Aii) ictal events. Note the progressive increase in the numbers of action potentials with each ictal crisis in the early event, contrasting with the instantaneous step change in firing at the start of the late event. Bi, The somatic $\mathrm{Ca}^{2+}$ signals (somatic signal with surround subtracted (center-surround signal), and normalized to the maxima), from the same three neurons at the onset of an early and a late event. Bii, The temporal derivative of the Ca signals for the same three neurons during the early and late events. To the right of the trace of cell 3 is a grayscale showing how the derivative plots for individual neurons are converted to the grayscale plot immediately below the trace. $C$, Grayscale plots for all of the neurons showing a clear $\mathrm{Ca}^{2+}$ signal within a $340 \times 340 \mu \mathrm{m}$ field of view. The data from two separate slices are shown, illustrating the staggered recruitment pattern during an early event ( $\boldsymbol{C}^{(i)}$, as evident when the maximal $\mathrm{d}(\Delta \mathrm{F}) / \mathrm{dt}$ is marked (Ci, right plot), and a late event (Cii) in which virtually every neuron is recruited in a single step, simultaneously across the entire field of view.

showed rapid generalization from the start of the recordings. Crucially, these slices had been preincubated for a prolonged period in $0 \mathrm{Mg}^{2+}$. We never detected rapid generalization in the earliest recorded events, suggesting that the slices in Wong and Prince's study that did show such rapid generalization had actually experienced many ictal events before the start of the recordings. Notably, this previous study used slices from adult guinea pig and reported the same range of velocities as we report here in slices taken from juvenile mice (postnatal day 13-18).

The rapid propagation in all disinhibition models (Chervin et al., 1988; Wadman and Gutnick, 1993; Albowitz et al., 1998; Pinto et al., 2005; Trevelyan et al., 2006), and also of late $0 \mathrm{Mg}^{2+}$ events, is simply explained by neurons succumbing to the first paroxysmal excitatory volley they experience. Pinto et al. (2005) showed that this rapid propagation is slowed by the glutamatergic antagonist DNQX, but appears not to be sensitive to additional suppression of inhibition. The modulation of propagation speed by DNQX is relatively small $(<10$-fold change) (Pinto et al. 2005) compared with the delays caused by the feedforward inhibition. We conclude therefore that this inhibitory restraint is the prime determinant of the rate at which in vitro epileptiform activity propagates. Given that interneuronal circuitry, being predomi- 
nantly local, is relatively preserved by slicing, we believe that the presence or absence of this critical inhibitory restraint may also explain the different rates at which seizures generalize in vivo (Jasper, 1969; Lemieux and Blume, 1986; Kobayashi et al., 1994; Blume et al., 2001; Timofeev and Steriade, 2004).

It should be noted that 4-aminopyridine (Weissinger et al., 2005) or $0 \mathrm{Ca}^{2+}$ ACSF (Konnerth et al., 1984) can also induce slowly propagating seizure-like events. The slow speed of propagation in this latter model has been attributed to nonsynaptic mechanisms, involving gap junctions, or diffusion of $\mathrm{K}^{+}$ions from the ictal wavefront, and thus appears unrelated to the inhibitory restraint that we propose.

Why would feedforward inhibition fail with successive ictal events? Studies using slices from entorhinal cortex bathed in 0 $\mathrm{Mg}^{2+}$ suggest that failure of feedforward inhibition coincides with an increased resistance to common antiepileptics; thus, it is crucial to understand the mechanisms behind this failure (Dreier and Heinemann, 1990; Pfeiffer et al., 1996; Dreier et al., 1998). This will require additional study because there are several reasons why the feedforward inhibition in late $0 \mathrm{Mg}^{2+}$ ictal events might fail. It could result either from reduced inhibition or from enhanced excitation. Possible causes for the former include presynaptic depletion (Bekkers and Stevens, 1990), a reduction in $\mathrm{GABA}_{\mathrm{A}}$ conductance (Thompson and Gahwiler, 1989; Whittington et al., 1995), increased threshold for activation of interneurons, changes in the metabolic processing of GABA after intense neuronal activation (Pfeiffer et al., 1996), internalization of $\mathrm{GABA}_{\mathrm{A}}$ receptors (Naylor et al., 2005), or even interneuronal death induced by the extreme activity during ictal events (Dinocourt et al., 2003). Enhanced excitation may result from potentiation during ictal events (Bernard and Wheal, 1996; Khalilov et al., 2005), because the combination of synchronous firing and freely conducting NMDA receptors should be a very powerful drive for synaptic modification. Some of these mechanisms may be specific to this particular in vitro model, whereas others, such as the ictal-induced modification of the network (synaptic or cell death) could also apply in vivo. Thus, as the inhibitory restraint fails, the recruitment of pyramids during each ictal crisis will increase, and the resultant increase in the local excitatory drive will enhance recruitment still further. For this reason, epileptiform activity will tend to evolve quickly from a slow propagation to a pattern of rapid generalization.

\section{References}

Albowitz B, Kuhnt U (1995) Epileptiform activity in the guinea-pig neocortical slice spreads preferentially along supragranular layers-recordings with voltage-sensitive dyes. Eur J Neurosci 7:1273-1284.

Albowitz B, Kuhnt U, Kohling R, Lucke A, Straub H, Speckmann EJ, Tuxhorn I, Wolf P, Pannek H, Oppel F (1998) Spatio-temporal distribution of epileptiform activity in slices from human neocortex: recordings with voltage-sensitive dyes. Epilepsy Res 32:224-232.

Anderson WW, Lewis DV, Swartzwelder HS, Wilson WA (1986) Magnesium-free medium activates seizure-like events in the rat hippocampal slice. Brain Res 398:215-219.

Badea T, Goldberg J, Mao B, Yuste R (2001) Calcium imaging of epileptiform events with single-cell resolution. J Neurobiol 48:215-227.

Bekkers JM, Stevens CF (1990) Presynaptic mechanism for long-term potentiation in the hippocampus. Nature 346:724-729.

Bernard C, Wheal HV (1996) A role for synaptic and network plasticity in controlling epileptiform activity in CAl in the kainic acid-lesioned rat hippocampus in vitro. J Physiol 495:127-142.

Blume WT, Ociepa D, Kander V (2001) Frontal lobe seizure propagation: scalp and subdural EEG studies. Epilepsia 42:491-503.

Chervin RD, Pierce PA, Connors BW (1988) Periodicity and directionality in the propagation of epileptiform discharges across neocortex. J Neurophysiol 60:1695-1713.
Cossart R, Aronov D, Yuste R (2003) Attractor dynamics of network UP states in the neocortex. Nature 423:283-288.

Dinocourt C, Petanjek Z, Freund TF, Ben-Ari Y, Esclapez M (2003) Loss of interneurons innervating pyramidal cell dendrites and axon initial segments in the CA1 region of the hippocampus following pilocarpineinduced seizures. J Comp Neurol 459:407-425.

Dreier JP, Heinemann U (1990) Late low magnesium-induced epileptiform activity in rat entorhinal cortex slices becomes insensitive to the anticonvulsant valproic acid. Neurosci Lett 119:68-70.

Dreier JP, Zhang CL, Heinemann U (1998) Phenytoin, phenobarbital, and midazolam fail to stop status epilepticus-like activity induced by low magnesium in rat entorhinal slices, but can prevent its development. Acta Neurol Scand 98:154-160.

Ikegaya Y, Aaron G, Cossart R, Aronov D, Lampl I, Ferster D, Yuste R (2004) Synfire chains and cortical songs: temporal modules of cortical activity. Science 304:559-564.

Jasper HH (1969) Mechanisms of propagation: extracellular studies. In: Basic mechanisms of the epilepsies, including hippocampus (Jasper $\mathrm{HH}$, Ward AA, Pope A, eds), pp 421-440. Boston: Little Brown.

Khalilov I, Le Van Quyen M, Gozlan H, Ben-Ari Y (2005) Epileptogenic actions of GABA and fast oscillations in the developing hippocampus. Neuron 48:787-796.

Kobayashi K, Nishibayashi N, Ohtsuka Y, Oka E, Ohtahara S (1994) Epilepsy with electrical status epilepticus during slow sleep and secondary bilateral synchrony. Epilepsia 35:1097-1103.

Konnerth A, Heinemann U, Yaari Y (1984) Slow transmission of neural activity in hippocampal area CA1 in absence of active chemical synapses. Nature 307:69-71.

Lemieux JF, Blume WT (1986) Topographical evolution of spike-wave complexes. Brain Res 373:275-287.

MacLean JN, Watson BO, Aaron GB, Yuste R (2005) Internal dynamics determine the cortical response to thalamic stimulation. Neuron 48:811-823.

Naylor DE, Liu H, Wasterlain CG (2005) Trafficking of GABA(A) receptors, loss of inhibition, and a mechanism for pharmacoresistance in status epilepticus. J Neurosci 25:7724-7733.

Pfeiffer M, Draguhn A, Meierkord H, Heinemann U (1996) Effects of gamma-aminobutyric acid (GABA) agonists and GABA uptake inhibitors on pharmacosensitive and pharmacoresistant epileptiform activity in vitro. Br J Pharmacol 119:569-577.

Pinault D, Leresche N, Charpier S, Deniau JM, Marescaux C, Vergnes M, Crunelli V (1998) Intracellular recordings in thalamic neurones during spontaneous spike and wave discharges in rats with absence epilepsy. J Physiol 509:449-456.

Pinto DJ, Patrick SL, Huang WC, Connors BW (2005) Initiation, propagation, and termination of epileptiform activity in rodent neocortex in vitro involve distinct mechanisms. J Neurosci 25:8131-8140.

Steriade M, Contreras D (1995) Relations between cortical and thalamic cellular events during transition from sleep patterns to paroxysmal activity. J Neurosci 15:623-642.

Thompson SM, Gahwiler BH (1989) Activity-dependent disinhibition. III. Desensitization and GABAB receptor-mediated presynaptic inhibition in the hippocampus in vitro. J Neurophysiol 61:524-533.

Timofeev I, Steriade M (2004) Neocortical seizures: initiation, development and cessation. Neuroscience 123:299-336.

Trevelyan AJ, Sussillo D, Watson BO, Yuste RM (2006) Modular propagation of epileptiform activity: evidence for an inhibitory veto in neocortex. J Neurosci 26:12447-12455.

Wadman WJ, Gutnick MJ (1993) Non-uniform propagation of epileptiform discharge in brain slices of rat neocortex. Neuroscience 52:255-262.

Walther H, Lambert JD, Jones RS, Heinemann U, Hamon B (1986) Epileptiform activity in combined slices of the hippocampus, subiculum and entorhinal cortex during perfusion with low magnesium medium. Neurosci Lett 69:156-161.

Weissinger F, Buchheim K, Siegmund H, Meierkord H (2005) Seizure spread through the life cycle: optical imaging in combined brain slices from immature, adult, and senile rats in vitro. Neurobiol Dis 19:84-95.

Whittington MA, Traub RD, Jefferys JG (1995) Erosion of inhibition contributes to the progression of low magnesium bursts in rat hippocampal slices. J Physiol 486:723-734.

Wong BY, Prince DA (1990) The lateral spread of ictal discharges in neocortical brain slices. Epilepsy Res 7:29-39. 